\title{
Thermogravimetric analysis of bamboo-tar under different heating rates based on distributed activation energy model
}

\author{
Huan Zhang ${ }^{1,2}$, Beibei Yan ${ }^{1}$, Tingzhou Lei ${ }^{1,3}$, Tao Liu ${ }^{4}$, jianjun $\mathrm{Hu}^{2}$, Yameng Li ${ }^{2}$ Guanyi Chen ${ }^{1 *}$ \\ (1. School of Environmental Science \& Engineering, Tianjin University, Tianjin 300350, China; \\ 2. Collaborative Innovation Center of Biomass Energy, Henan Agricultural University, Zhengzhou 450002, China; \\ 3. Energy Institute, Henan Academy of Sciences, Zhengzhou 450002, China; \\ 4. College of Resources and Environment, Henan University of Economics and Law, Zhengzhou 450002, China)
}

\begin{abstract}
Carbon fiber is a kind of new polymer material with excellent mechanical properties and being applied widely. The process of carbon fiber prepared by bamboo tar, including extraction, condensation, spinning, oxidation and carbonation, is influenced by the pyrolysis kinetics significantly. In this paper, the thermogravimetric analysis (TGA) of bamboo tar produced in the process of pyrolysis and gasification of the bamboo which is known as Phylostachys sulphurea, was analyzed by the distributed activation energy model (DAEM) to understand the kinetic properties and parameters of bamboo tar. The thermogravimetric analysis of bamboo tar which is used as the raw material of carbon fiber was conducted under 5 different heating rates (i.e. $5,10,15,30$ and $50{ }^{\circ} \mathrm{C} / \mathrm{min}$, etc.) in nitrogen atmosphere. The results show that the activation energy of bamboo tar and the exponential factor increased significantly with the increase of the heating rate, and the low heating rate is advantageous to the extraction of bamboo tar solvent and the thermal polycondensation, which can provide scientific reference for the optimization of carbon fiber technology. The thermal weight results show that the temperature range of bamboo tar being decomposed rapidly is $213^{\circ} \mathrm{C}-410^{\circ} \mathrm{C}$. The ranges of the activation energy were calculated by DAEM, which have small difference in comparisons with five heating rates when the conversion rate is at 0.1-0.6 and the average value of the activation energy is $119 \mathrm{~kJ} / \mathrm{mol}$. The stability range of the activation energy is enlarged when the conversion rate is greater than 0.6 and heating rate increases.
\end{abstract}

Keywords: bamboo tar, carbon fiber, thermogravimetric analysis (TGA), distributed activation energy model (DAEM) DOI: $10.25165 /$ j.ijabe.20181106.3839

Citation: Zhang H, Yan B B, Lei T Z, Liu T, Hu J J, Li Y M, et al. Thermogravimetric analysis of bamboo-tar under different heating rates based on distributed activation energy model. Int J Agric \& Biol Eng, 2018; 11(6): 180-186.

\section{Introduction}

Biomass is typically referring to a type of renewable energy created from the photosynthesis of plants, which uses carbon dioxide, water and solar energy to produce carbohydrates. Green plants convert solar energy into chemical energy by the use of chlorophyll and store this energy in the biomass, where each mole of carbon fixed represents about $470 \mathrm{~kJ}$ of energy absorbed ${ }^{[1,2]}$. Biomass is generally composed of carbon, hydrogen, oxygen, nitrogen and other components of the complex hydrocarbons derived from plant, animal and microorganism renewable $\operatorname{organics}^{[3,4]}$, and it can be converted into conventional solid, liquid and gaseous fuels.

Currently, biomass conversion methods includes gasification, liquefaction, briquetting and direct combustion ${ }^{[5,6]}$. The study of

\section{Received date: 2017-09-20 Accepted date: 2018-09-06}

Biographies: Huan Zhang, $\mathrm{PhD}$ candidate, research interest: biomass energy, Email: zhanghuan5754@163.com; Beibei Yan, Associate Professor, research interest: biomass gasification, Email: yanbeibei@tju.edu.cn; Tingzhou Lei, Professor, research interest: biomass energy; Tao Liu, $\mathrm{PhD}$, research interest: indoor mapping, Email: liutao@huel.edu.cn; Jianjun Hu, Professor, research interest: biomass gasification, Email: hu.jianjun@163.com; Yameng Li, PhD candidate, research interest: biological hydrogen production, Email: 874750357@qq.com.

*Corresponding author: Guanyi Chen, Professor, research interest: biomass gasification. School of Environmental Science \& Engineering, Tianjin University, Tianjin 300350, China. Tel: +86-13512208049, Email: chen@tju.edu.cn. biomass gasification began from the year of 1883, and became a research hotspot in recent years. In the early days, it provided power to automotive or agricultural irrigation machinery, using charcoal as raw material and driving the engine with the gasification gas. Because of a fuel shortage, Germany developed the car engine gasifier for civilians. After World War II, the Middle East provided cheap and high-quality oil to the world, which made it become the primary energy of almost all developed countries. Biomass gasification regained attention after the oil crisis occurred in the 1970s.

Biomass tar is one of the byproducts from the process of biomass pyrolysis and gasification. There is not a uniform definition of what it is, and scholars from various countries have different understandings ${ }^{[7]}$. The U.S. and EU experts define it as a mass with a relative molecular mass greater than benzene organics $^{[8]}$. Chinese scholars ${ }^{[9]}$ think that the tar should include macromolecules, including benzene and aromatic hydrocarbon organics. Thermochemical conversion technology is widely used in extracting useful carbon materials through the conversion of biomass pyrolysis tar. The activated carbon materials and products made of biomass tar exhibit high specific surface area and good mechanical properties. The preparation of tar-based carbon fiber was done by pretreating the feedstock with solvent followed by heated filtering. Then, the isotropic tar samples were obtained from thermal refining and modification with the help of the polycondensation reaction of the biomass tar. The molten tar samples at high temperature were sent to the spinning jet with a high-pressure pump, the gushing filaments were simultaneously 
cooled with the help of high speed gas flow and drawn into filaments. The products of tar-based carbon fiber were then obtained by pre-oxidation and high temperature carbonization.

Bamboo belongs to Wood family (Peaceae) Bambusoideae (Bambusaideae), is a perennial woody plant with rapid growth, high reproductive and regeneration ability, high output, high mechanical strength, strong adaptability and other characteristics. It is an ideal renewable resources. The world's bamboo is about 70 genera and more than 1200 species, occupied an area of about 22 million $\mathrm{hm}^{2}$ and widely distributed in Asia, South America, Oceania, Africa and other regions ${ }^{[10]}$. China and Southeast Asia are the central areas of bamboo. Bamboo energy utilization methods mainly include: Bamboo plant power generation technology, bamboo waste as industrial boiler fuel, the production of bamboo charcoal and bio-fuel technology ${ }^{[11]}$. At present, China's bamboo forest area was about 4.21 million $\mathrm{hm}^{2}$, each year can fell more than 500 million branches, more than 3 million $t$ of miscellaneous bamboo, which is equivalent to more than 10 million $\mathrm{m}^{3}$ wood and was widely used in the car floor, floor, building model, furniture and many other aspects. But its actual utilization rate is lower, only for the cutting volume of about $30 \%$. In recent years, 3 major world problems, such as energy, environment and materials, have led to a bright research hotspot in biomass energy and biomass materials. Furthermore, the research on the related technologies processing resource-rich bamboo residues to the biomass energy and biomass based materials became a recent research hot spot, especially the bamboo charcoal and gas technology and the adsorption properties (Figure 1) of the bamboo charcoal by the pyrolysis process ${ }^{[12-14]}$. Countries involved in early development of bamboo charcoal preparation and bamboo charcoal performance related research are mainly Japan, Korea, Indonesia and other countries ${ }^{[15]}$. Since 1995, China's Zhejiang, Fujian and other places began to fire bamboo charcoal, and developed a series of bamboo charcoal products ${ }^{[16]}$. However, in the pyrolysis process of bamboo charcoal, there is a certain amount of bamboo tar, generally as the pyrolysis waste, is not used. Arbitrary disposal will cause environmental pollution and waste of agricultural and forestry resources.

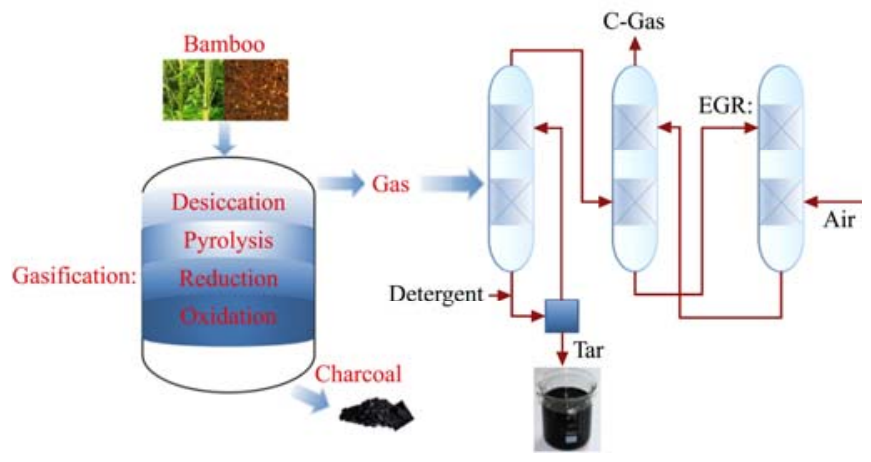

Note: C-Gas: cleangas; EGR: exhaust gas recirculation.

Figure 1 Gasification processdiagram of the bamboobiomass

Qiao et al. ${ }^{[17]}$ proposed a method of preparing carbon fiber from bamboo biomass tar. The elemental analysis of bamboo biomass tar showed a carbon content of up to $62 \%$, the carbon fiber of bamboo biomass tar showed a tensile strength in the range of 340-620 MPa and a modulus range of 27-44 GPa. Prauchner et al. indicated a fiber diameter of $27 \mathrm{MPa}$ and a fiber tensile modulus of $14 \mathrm{GPa}$ when testing the isotropic tar-based carbon fibers ${ }^{[18]}$. Therefore, the bamboo tar can be thought of as having a huge potential in the production of tar-based carbon fiber.
However, the related research on bamboo tar gasification and pyrolysis of the product is still in the initial stage, especially the study of bamboo tar to produce high grade energy or material utilization is rarely reported. Therefore, to understand the bamboo gasification tar, a lot of basic research on the pyrolysis behavior of bamboo tar can achieve the purpose of making full use of bamboo resources and converting them into high grade energy or nanometer carbon fiber materials.

Heating rate is one of the important thermal parameters affecting the process of carbon fiber preparation. The high heating rate is advantageous to the fracture of the bond, and the low heating rate will result in the reconnection of the organic volatile fragments in the carbonization process of tar materials ${ }^{[19]}$. At high temperature, the fast heating rate makes the tar small molecule matter precipitate rapidly, the volatile concentration is released, which increases the pore specific surface area of the coke ${ }^{[20]}$ and strengthens the carbonization stage in the carbon fiber preparation process. Through the thermogravimetric analysis (TGA) of bamboo tar produced in the pyrolysis and gasification process of Phyllostachys sulphurea bamboo, the pyrolysis kinetics of bamboo tar was studied by the distributed activation energy model (DAEM). The objective of this study was to study the thermal degradation mechanism of biomass-derived tar in order to better control, separate and utilize this promising biomaterial. The thermal degradation process was analyzed by thermogravimetry using multi-heating rates at non-isothermal conditions. The relationship between the structure and thermal properties of bamboo tar was also discussed.

\section{Materials and methods}

\subsection{Materials}

The bamboo tar used in the experiment was produced from Institute of Chemical Industry of Forestry Products, Chinese Academy of Forestry. It is derived from the byproduct of the pyrolysis process of Phyllostachys sulphurea bamboo under $450^{\circ} \mathrm{C}-600^{\circ} \mathrm{C}$ conditions. The bamboo tar samples was processed through pretreating for 20-30 min by centrifuge with $5000 \mathrm{r} / \mathrm{min}$, placing $2 \mathrm{~h}$, filtering out impurities by filter cloth and placing $48 \mathrm{~h}$ in a drying oven under $80^{\circ} \mathrm{C}$. The composition and structural properties of bamboo tar samples were analyzed by a Vario MACRO cube v2.0.9 elemental analyzer based on China's national standards (GB/T 21923-2008 General testing rules for solid biofuels, GB/T 28734-2012 Determination of carbon and hydrogen in solid biofuels, GB/T 30728-2014 Determination of nitrogen and oxygen in solid biofuels ${ }^{[21-23]}$ ) as shown in Table 1. The rate of carbon and hydrogen $(\mathrm{C} / \mathrm{H})$ is 0.57 , and the rate of carbon and oxygen $(\mathrm{C} / \mathrm{O})$ is 2.9. The elemental analysis of bamboo tar samples showed that the higher oxygen content was $22.41 \%$.

Table 1 Elemental analysis for bamboo tar

\begin{tabular}{cccccc}
\hline $\mathrm{C}(\mathrm{wt} \%)$ & $\mathrm{H}(\mathrm{wt} \%)$ & $\mathrm{N}(\mathrm{wt} \%)$ & $\mathrm{O}(\mathrm{wt} \%)$ & $\mathrm{C} / \mathrm{H}$ & $\mathrm{C} / \mathrm{O}$ \\
\hline 65 & 7.46 & 0.52 & 22.41 & 0.57 & 2.9 \\
\hline
\end{tabular}

\subsection{Thermogravimetric analysis of bamboo tar}

Thermal analysis (TGA) of bamboo tar samples was studied under atmospheric pressure by using TGA or differential thermal analysis (DTA) analyzer (SDT- Q600, TA instruments, USA). The experimental parameters were as follow: calorimetry accuracy was $\pm 2 \%$, measuring range was $0-200 \mathrm{mg}$, balance sensitivity was $\pm 0.1 \mu \mathrm{g}$, DTA sensitivity was $\pm 0.001^{\circ} \mathrm{C}$, temperature range was from room temperature to $1500^{\circ} \mathrm{C}$, flow rate constant of nitrogen as 
a protective gas was $100 \mathrm{~mL} / \mathrm{min}$ under the condition that the heating rate is less than $50^{\circ} \mathrm{C} / \mathrm{min}^{[24]}$. The bamboo tar samples of 5-10 mg were placed in alumina crucible. The bamboo tar samples were heated from $30^{\circ} \mathrm{C}$ to $800^{\circ} \mathrm{C}$ under conditions of 5,10 , $15,30,50{ }^{\circ} \mathrm{C} / \mathrm{min}$ respectively. In order to prevent the possible secondary reaction of the volatile and coke at a higher temperature, the weight loss data of the bamboo tar samples were used as an experimental analysis in this study in the temperature range between $100^{\circ} \mathrm{C}$ and $675^{\circ} \mathrm{C}^{[25]}$.

\subsection{Pyrolytic kinetic modeling}

The pyrolysis reaction of the bamboo tar samples occurred in the temperature programmed, and the pyrolysis conversion rate can be expressed as a first-order kinetic Equation $(1)^{[26]}$ :

$$
\mathrm{d} \alpha / \mathrm{d} t=K(T) f(\alpha)
$$

where, $K$ is reaction rate constant; $T$ is temperature; $f(\alpha)$ is the reaction mechanism function; $\mathrm{d} \alpha / \mathrm{d} t$ is the pyrolysis conversion rate of bamboo tar, and $\alpha$ is the weight loss rate of bamboo tar at time $t$. $\alpha$ can be obtained by Equation (2):

$$
\alpha=\left(W_{0}-W_{t}\right) /\left(W_{0}-W_{f}\right)
$$

where, $W_{0}, W_{t}$ and $W_{f}$ are the initial quality of samples, $t$-time quality and final quality, respectively. According to Arrhenius law, the reaction rate constant can be expressed as:

$$
K(T)=A \exp (-E / R T)
$$

where, $A$ is the frequency factor, $\mathrm{S}^{-1} ; R$ is the molar gas constant, $8.314 \mathrm{~J} /(\mathrm{K} \cdot \mathrm{mol}) ; E$ is apparent activation energy, $\mathrm{kJ} / \mathrm{mol}$; and $T$ is absolute temperature, $K$. The kinetic Equation (4) can be obtained by Equations (1) and (3).

$$
(d \alpha / d t)=A \exp \left(-\frac{E}{R T}\right) f(\alpha)
$$

Thermodynamic analysis usually adopts isothermal or nonisothermal experiments. The isothermal test is done in a narrow temperature range and it is difficult to obtain the real isothermal condition under the low and high reaction schedule. The non-isothermal method is suitable for being applied in the wide temperature range, and detecting the complex quality of the multi-step solid-state reaction process ${ }^{[27]}$. The heating rate of bamboo tar can be defined by the equation in the dynamic non-isothermal method. Therefore, the three dynamic factors and can expression by Equation (5):

$$
d \alpha / d T=A / \beta \exp \left(-\frac{E}{R T}\right) f(\alpha)
$$

\subsection{Model based procedure of DAEM}

Thermal weight loss of bamboo tar is an important process for the carbonization process of carbon fiber preparation and has important influence on its carbonization reaction activity and transformation process. The thermogravimetric analysis method of bamboo tar mainly includes the method of constant temperature and temperature programming. The temperature programming method has been widely used because only one or several weightless curves can get the distribution of kinetic parameters throughout the temperature range. In order to obtain the thermal kinetic parameters of bamboo tar, a variety of bamboo tar pyrolysis model of single reaction, dual competition reaction, finite multi-parallel reaction, infinite multi-parallel reaction and so on have been developed.

The single reaction model considers that the pyrolysis process of bamboo tar is approximately the first or n-stage reaction, and the single reaction model can only obtain the average of a certain temperature range. The application of the dual competitive reaction model is limited because it has 6 undetermined parameters.
The finite parallel reaction model considers that the pyrolysis of bamboo tar is the thermal decomposition of one or several compounds, and the number of parallel reactions can be determined by empirical tests. The pyrolysis reactions of bamboo tar as a complex polymer is considered to be composed of an infinite number of parallel primary reactions and its activation energy has a continuous distribution, called DAEM. It can be good prediction of the thermal kinetic parameters. The DAEM can be used to predict thermodynamic parameters commendably. It was originally proposed by $\mathrm{Vand}^{[28]}$, which was used to describe the development of complex reaction ${ }^{[29]}$. The method considered countless parallel irreversible a-level reactions ${ }^{[30,31]}$, assumed individual activation energy for each parallel reaction, and a continuous distribution function, DAEM, as shown in Equation (6):

$$
1-\alpha=\int_{0}^{\infty} \exp \left(-A \int_{0}^{t} e^{-E / R T} d t\right) f(E) d E
$$

where, $\alpha$ is the pyrolysis of bamboo tar at any time $t$ when the rate of weight loss, frequency factor corresponding to the activation energy, activation energy distribution function, to reflect the differences in the parallel first-order reaction activation energy, and satisfy the $\int_{0}^{\infty} f(E) \mathrm{d} E=1$ condition. Using the Miura step function approximation (integration) theory, the Equation (6) can be simplified as Equation (7):

$$
\operatorname{Ln}\left(\beta / T^{2}\right)=\operatorname{Ln}\left(\frac{A R}{E}\right)+0.6075-E / R T
$$

In terms of $\alpha$ given, $E$ and $A$ are obtained by making $\operatorname{Ln}\left(\beta / T^{2}\right)$ and $1 / T$ correlation diagrams, thus the activation energy $E$ and the frequency factor $A$ were obtained. Each activation energy $E$ and the frequency factor A can be obtained by repeating the above steps relative to different weightlessness rates $\alpha$. The activation energy change curve of bamboo tar during the process of thermal weightlessness was obtained by the correlation diagram of the weightlessness rate $\alpha$ to activation energy $E$. The activation energy distribution function $f(E)$ can be obtained according to weight loss rate $\alpha$ for differential calculation of activation energy $E$. Therefore, when using the DAEM method to analyze the thermal dynamics of bamboo tar, at least three groups of parallel reaction experimental data were required. Five different heating rates (5, $10,15,30$ and $50{ }^{\circ} \mathrm{C} / \mathrm{min}$ ) were selected for the thermogravimetric analysis of bamboo tar in this study.

\section{Results and discussion}

\subsection{Pyrolysis characteristics}

The DAEM method has been widely used for the thermal kinetic analysis of biomass, including agricultural residues ${ }^{[32]}$, $\operatorname{wood}^{[33]}$ and pyrolysis products from fowl dropping ${ }^{[34]}$. The results of the thermogravimetric analysis of bamboo tar under the condition of different heating rates $\left(5,10,15,30\right.$ and $\left.50{ }^{\circ} \mathrm{C} / \mathrm{min}\right)$ are shown in Figure 2. When the heating rate is 5, 10 and 15 ${ }^{\circ} \mathrm{C} / \mathrm{min}$, respectively, the slow and equal interval weight losses of bamboo tar samples were compared as shown in Figure 2a. Whereas, when the heating rate is $5,30,50$ and $10,30,50{ }^{\circ} \mathrm{C} / \mathrm{min}$, respectively, the fast and non-equal interval weight losses of bamboo tar samples were compared as shown in Figure $2 b$ and Figure 2c.

The pyrolytic process of bamboo tar samples can be divided into three main stages: preheating solution for water loss, main pyrolysis and carbonization, etc. The results of the thermogravimetric analysis of bamboo tar in each stage were shown in Table 2. 


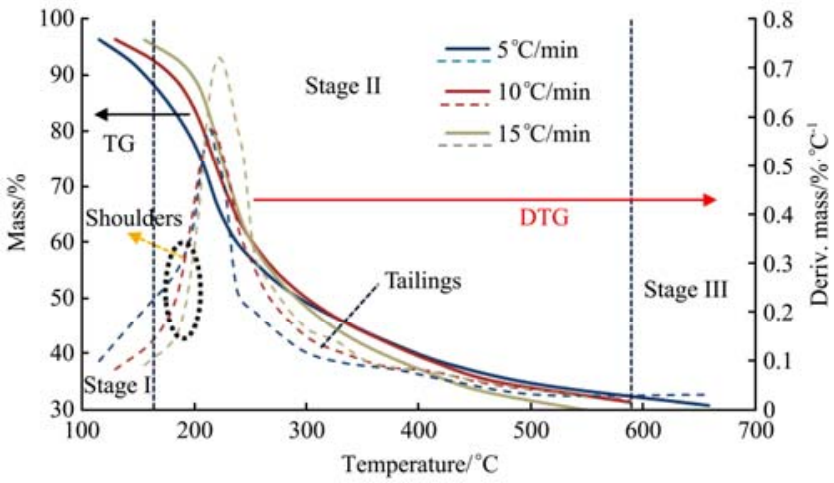

a. Heating rates $=5,10,15^{\circ} \mathrm{C} / \mathrm{min}$

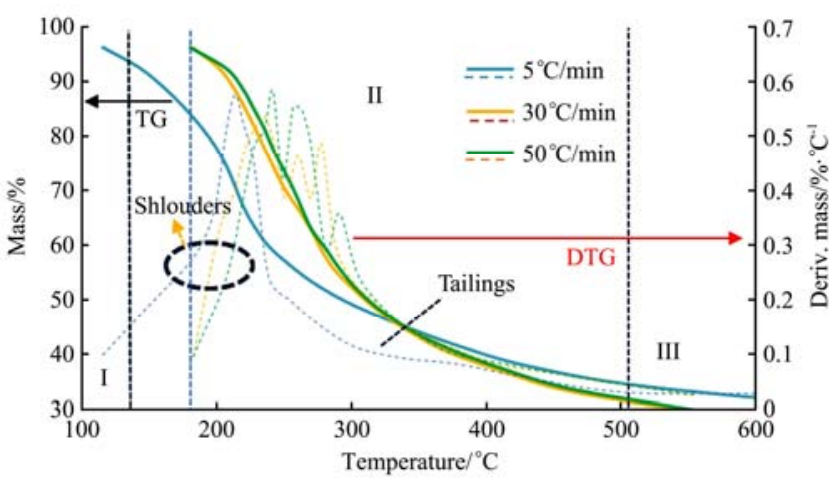

b. Heating rates $=5,30,50^{\circ} \mathrm{C} / \mathrm{min}$

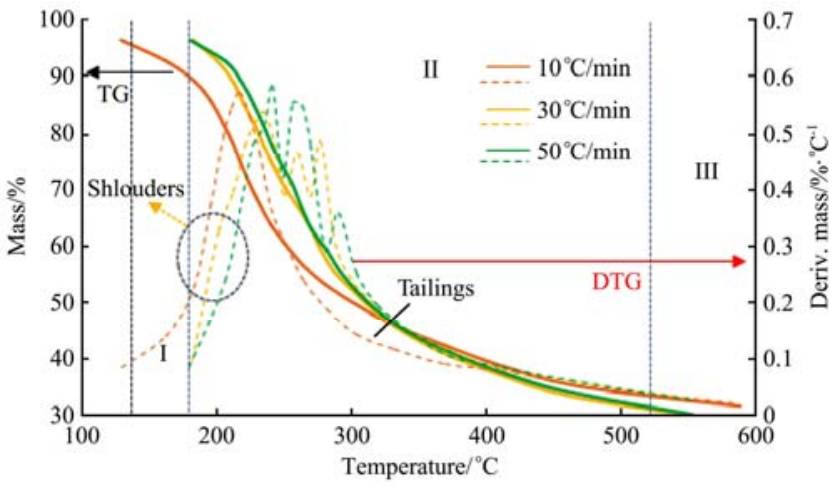

c. Heating rates $=10,30,50^{\circ} \mathrm{C} / \mathrm{min}$

Figure 2 TG and DTG profiles at heating rates of bamboo tar

Table 2 Weight loss and final residue rate of bamboo biomass tar during pyrolysis

\begin{tabular}{ccccc}
\hline \multirow{2}{*}{$\begin{array}{c}\text { Heating rate } \\
/{ }^{\circ} \mathrm{C} \cdot \mathrm{min}^{-1}\end{array}$} & $\begin{array}{c}\text { Loss of weight at all stages/\% } \\
\text { Dehydration preheating } \\
\text { solution stage }\end{array}$ & $\begin{array}{c}\text { Main pyrolysis } \\
\text { stage }\end{array}$ & $\begin{array}{c}\text { Carbonizatio } \\
\text { n stage }\end{array}$ & $\begin{array}{c}\text { Residue } \\
\text { rate/\% }\end{array}$ \\
\hline 5 & 6 & 52.25 & 7.17 & 34.58 \\
10 & 4.61 & 55.39 & 7.75 & 32.25 \\
15 & 2.95 & 58.73 & 6.14 & 32.18 \\
30 & 1.24 & 61.68 & 5.22 & 31.86 \\
50 & 1 & 65 & 5.12 & 28.88 \\
\hline
\end{tabular}

The preheating solution for water loss of bamboo tar samples mainly occurs in the low temperature region $\left(131{ }^{\circ} \mathrm{C}-176^{\circ} \mathrm{C}\right)$ as shown in Figure 2 "Stage I", in which weight loss is less and the weightless substance is mainly the water vapor and light volatile evaporation of bamboo tar samples. The main pyrolysis stage of bamboo tar samples covers a wide temperature range as shown in Figure 2 "Stage II". The DTG curve indicates a significant weight loss peak at $213^{\circ} \mathrm{C}$ with heating rate of $5{ }^{\circ} \mathrm{C} / \mathrm{min}$ and $226^{\circ} \mathrm{C}$ with heating rate of $15{ }^{\circ} \mathrm{C} / \mathrm{min}$, respectively. The higher thermal decomposition rate is shown in the temperature range. Due to the hysteresis effect of heat transfer, the temperature of shoulder and tail peaks is shifted to high temperature with the increase of heating rate after $400^{\circ} \mathrm{C}$, and the DTG peak height decreases with the increase of the rate. At high heating rates such as $30^{\circ} \mathrm{C} / \mathrm{min}$ and $50{ }^{\circ} \mathrm{C} / \mathrm{min}$, there are many weightlessness peaks $\left(231^{\circ} \mathrm{C}-300^{\circ} \mathrm{C}\right)$ in the bamboo tar samples, and the TG curves appear to coincide, which indicates that higher heating rate is advantageous for the main pyrolysis reaction stage of bamboo tar samples. and the weightlessness rate of bamboo tar samples in the main pyrolysis stage when the heating rate is $5{ }^{\circ} \mathrm{C} / \mathrm{min}$ than the weightlessness rate when the higher heating rate was lower than $10 \%$, and the end temperature of main pyrolysis reaction is also lower than $100^{\circ} \mathrm{C}$, but the maximum weight loss rate of main pyrolysis reaction is basically close, which indicates that the effect of heating rate on the maximum weight loss of the main pyrolysis reaction of bamboo tar samples is less. At the carbonization of bamboo tar samples as shown in Figure 2 "Stage III", the end temperature of bamboo tar samples was $650^{\circ} \mathrm{C}, 600^{\circ} \mathrm{C}, 550^{\circ} \mathrm{C}$ in turn with heating rate of $5{ }^{\circ} \mathrm{C} / \mathrm{min}, 10{ }^{\circ} \mathrm{C} / \mathrm{min}$, and $15{ }^{\circ} \mathrm{C} / \mathrm{min}$, respectively. The end temperature of bamboo tar samples was $550^{\circ} \mathrm{C}$ with heating rate of $30{ }^{\circ} \mathrm{C} / \mathrm{min}$ and $50{ }^{\circ} \mathrm{C} / \mathrm{min}$, which is close to that with heating rate of $15{ }^{\circ} \mathrm{C} / \mathrm{min}$. This shows that the heating rate higher than $15^{\circ} \mathrm{C} / \mathrm{min}$ has less effect on the end temperature of bamboo tar samples.

The residue rate of bamboo tar samples in carbonization stage decreases with the increase of heating rate as shown in Table 2, which indicates that proper raising of heating rate is propitious to accelerate the pyrolysis reaction rate of bamboo tar samples. At the same time, the trend of the DTG curve of thermal weightlessness is shifted laterally to the higher temperature direction, and the DTG curve peak of thermal weightlessness decreases with the increase of heating rate, which indicates that the pyrolysis rate of bamboo tar samples is affected by the synergistic effect of the heat and mass transfer process. The characteristic temperatures of weight loss were shown in Table 3.

\section{Table 3 Characteristic temperatures of weight loss}

\begin{tabular}{cccc}
\hline Stage & I & II & III \\
\hline Temperature $/{ }^{\circ} \mathrm{C}$ & $131-176$ & $213,226 \ldots$ & 550 \\
\hline
\end{tabular}

\subsection{Correlation between heating rate and weight loss rate}

During the pyrolysis process of bamboo tar samples, different heating rates (i.e. $5,10,15,30,50{ }^{\circ} \mathrm{C} / \mathrm{min}$ ) associated with the pyrolysis conversion rate were shown in Figure 3. It can be seen from Figure 3 that before $320^{\circ} \mathrm{C}$, lower heating rate leads to higher pyrolysis weight loss rate of bamboo tar samples. The pyrolysis rate curve of bamboo tar samples with different heating rates between $320^{\circ} \mathrm{C}-410^{\circ} \mathrm{C}$ is basically coincident, which indicates that the pyrolysis rate of bamboo tar samples is not affected by the heating rate. After $410^{\circ} \mathrm{C}$, the pyrolysis rate of bamboo tar samples increased slightly with the increase of heating rate, but the increment value was not significant. The change trend of heating rate and pyrolysis rate of bamboo tar samples should be obvious under slow heating rates (i.e. $5{ }^{\circ} \mathrm{C} / \mathrm{min}, 10^{\circ} \mathrm{C} / \mathrm{min}, 15^{\circ} \mathrm{C} / \mathrm{min}$ ), but the pyrolysis rate curve of bamboo tar sample did not change significantly under the rapid heating rate (i.e. $30{ }^{\circ} \mathrm{C} / \mathrm{min}$, $50{ }^{\circ} \mathrm{C} / \mathrm{min}$ ), showed that the heating rate had a greater influence on the thermal weightlessness rate of bamboo tar samples. Before $320^{\circ} \mathrm{C}$, the greater weight loss rate of bamboo tar samples can be obtained when heating rate is lower. 


\subsection{Distributed activation energy model parameters}

When bamboo tar was used to prepare carbon fiber materials, the carbonization reaction activity of bamboo tar samples was significantly demonstrated through the thermal weightlessness behavior of the carbonization process. The relationship between the weight loss rate and activation energy of bamboo tar samples at different heating rate can be obtained by using distribution activation energy model, which has a significant influence on the carbonization process of bamboo tar samples. The Arrhenius curve of bamboo tar samples was drawn using distribution activation energy model under different heating rate conditions as shown in Figure 4.

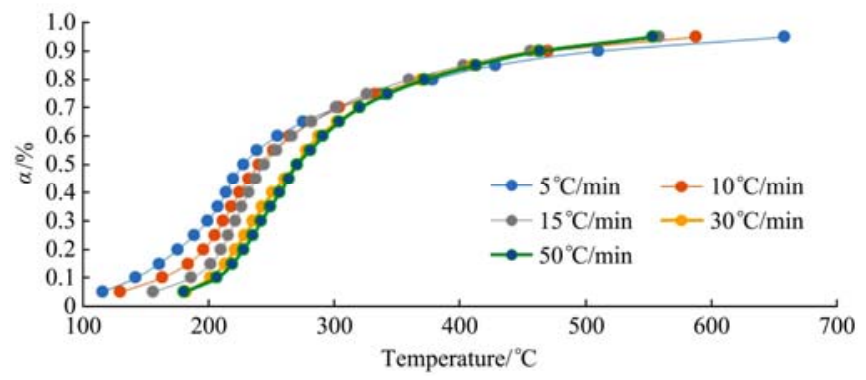

Figure 3 Temperature dependence of the extent of conversion $(\alpha)$ for different heating rates

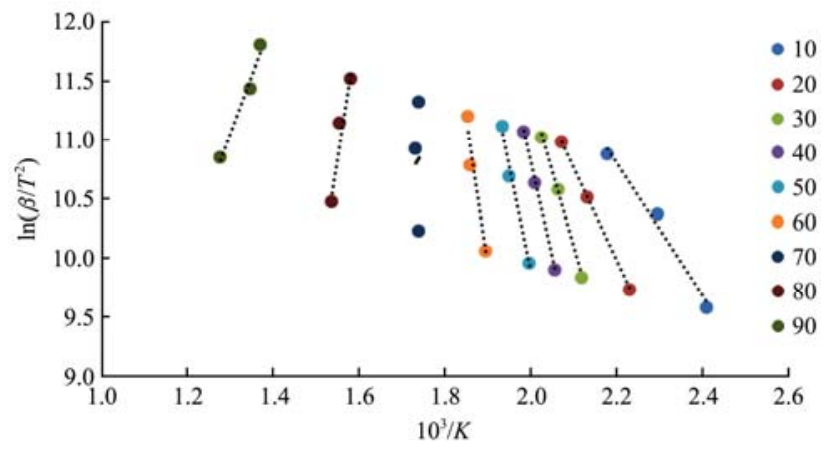

a. Heating rates $=5,10,15^{\circ} \mathrm{C} / \mathrm{min}$

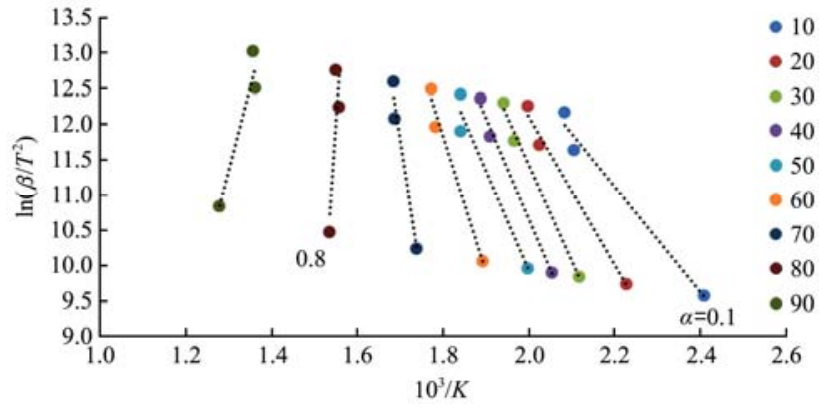

b. Heating rates $=5,30,50^{\circ} \mathrm{C} / \mathrm{min}$

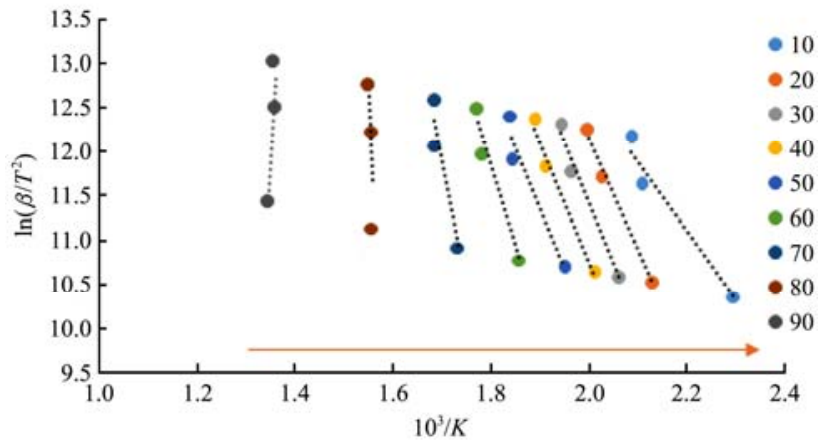

c. Heating rates $=10,30,50{ }^{\circ} \mathrm{C} / \mathrm{min}$

Figure 4 Arrhenius plots at selected conversion rates by the DAEM method
The slow and equal interval thermal weight loss rate of bamboo tar samples was within the scope of 0.1-0.6 with heating rate of $5,10,15^{\circ} \mathrm{C} / \mathrm{min}$, respectively. It was similar to the slope of the Arrhenius curve and had obvious linear parallel relations, and the activation energy can be in a certain continuous distribution as shown Figure 4a. Therefore, when the thermal weight loss rate reaches 0.6 , the thermal physical properties of the bamboo tar samples can be approximately described as multiple parallel primary reactions. The slope of the Arrhenius curve is larger when the thermal weight loss rate is greater than 0.6 , and it was no longer linearly parallel relationship with the Arrhenius curve when it was less than 0.6. This shows that with extremely complex multiple parallel multistage reaction mechanism, pyrolysis reaction has exceeded the application range of the approximate assumption of multiple parallel first order reaction in the distributed activation energy model ${ }^{[35]}$.

From Figures $4 \mathrm{~b}$ and $4 \mathrm{c}$, it can be found that when the heating rate falls in group $\mathrm{b}\left(5,30,50{ }^{\circ} \mathrm{C} / \mathrm{min}\right)$ and group $\mathrm{c}(10,30$, $50{ }^{\circ} \mathrm{C} / \mathrm{min}$ ) respectively, the fast and non-equal interval thermal weight loss rate of bamboo tar samples was within the scope of (0.1-0.7) and (0.1-0.8) in turn. It has a linear parallel relationship with the Arrhenius curve corresponding to each thermal weight loss rate, which conforms to the approximate assumption of multiple parallel first-order reactions in the distribution activation energy model. When the weight loss rate exceeds 0.7 or 0.8 respectively, the curve of thermal weight loss rate was no longer linearly parallel with the Arrhenius curve, and the activation energy of the bamboo tar samples can vary greatly. The activation energy distribution of bamboo tar samples can be changed by increasing the heating rate, but is not conform to the approximate assumption about the multiple parallel first order in the distributed activation energy model. Its research should be carried out in a complex multi-level reaction mechanism obviously ${ }^{[36]}$.

According to the Arrhenius curve of bamboo tar samples under different heating rate, the relationship between the thermal weight loss rate and the mean apparent activation energy can be obtained as shown in Figure 5.

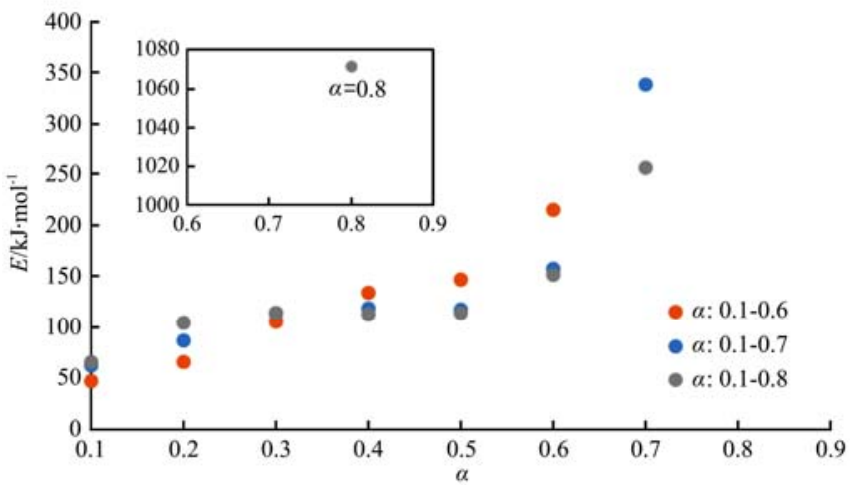

Figure 5 Activation energy (E) plotted against the extent of conversion rate $(\alpha)$

When the heating rate is $5{ }^{\circ} \mathrm{C} / \mathrm{min}$ and the thermal weight loss rate is within the scope of 0.1-0.6, the mean apparent activation energy is $119 \mathrm{~kJ} / \mathrm{mol}$ in the pyrolysis process of the bamboo tar samples. But when the heating rate increases to $10{ }^{\circ} \mathrm{C} / \mathrm{min}$ and the thermal weight loss rate is within the scope of $0.1-0.6$, the mean apparent activation energy is $142 \mathrm{~kJ} / \mathrm{mol}$ in the pyrolysis process of the bamboo tar samples. The mean apparent activation energy can increase to $248 \mathrm{~kJ} / \mathrm{mol}$ in the pyrolysis process of the bamboo 
tar samples when the heating rate is $15^{\circ} \mathrm{C} / \mathrm{min}$ and the thermal weight loss rate is within the scope of 0.1-0.6. The activation energy in the pyrolysis process of the bamboo tar samples can increase with the increase of heating rate and the range of thermal weight loss rate. Therefore, the thermal weight loss rate and average apparent activation energy can increase remarkably with higher heating rate in the pyrolysis process of bamboo tar samples.

\section{Conclusions}

The thermal decomposition process of bamboo tar can be divided into three main stages: water loss preheating, main pyrolysis and carbonization. In water loss preheating stage, bamboo tar can be decomposed at lower temperature range of $115^{\circ} \mathrm{C}-190^{\circ} \mathrm{C}$. In main pyrolysis stage, the heating rate has less influence on the maximum weight loss rate of the main pyrolysis reaction in the pyrolysis process of bamboo tar samples. In carbonization stage, the heating rate has less influence on the end pyrolysis temperature of bamboo tar samples when the heating rate exceeds $15^{\circ} \mathrm{C} / \mathrm{min}$.

There is a significant relationship between heating rate and thermal weight loss rate, and the thermal weight loss rate can be increased remarkably with higher heating rate in the pyrolysis process of bamboo tar samples. The thermogravimetric characteristics of bamboo tar were considered to be the theoretical basis of the thermal preparation process for tar-based carbon fiber.

When the heating rate was lower and the thermal weight loss rate was within the scope of 0.1-0.6, the mean apparent activation energy of the bamboo tar samples was $119 \mathrm{~kJ} / \mathrm{mol}$ in the pyrolysis process, and the thermodynamic analysis of bamboo tar can be carried out by using single reaction mechanism according to the distributed activation energy model. The average apparent activation energy can be increased remarkably with higher heating rate. In order to simplify the thermal physical analysis of bamboo tar samples, its research should be mainly focused on the weight loss rate range of 0.1-0.6 and the activation energy range of $109-119 \mathrm{~kJ} / \mathrm{mol}$ to understand the thermal properties of carbon fiber materials prepared by bamboo tar. The DAEM method reflected the whole thermal reaction process by a set of first-order single reactions, considering the complex compositions of the tar. It was suggested that volatilization as well as reactions like polymerization and condensation occurred during the thermal degradation process of the tar under the inert atmosphere.

\section{Acknowledgments}

This work was financially supported by the National Natural Science Foundation of China (551376056) "Study of regulation mechanisms and photo-thermal properties of photosynthetic hydrogen production under the condition of multiphase biomass flow". The authors would like to thank Prof. Qinglin Wu of Louisiana State University (U.S.A) and Prof. Xumeng Ge of Ohio State University (U.S.A) for their assistance on this project.

\section{[References]}

[1] Yuan H, Duan L, Qiu Y, Gao L, Zhang P, Cao R, et al. Response of son astrocytes and neurons to hyperosmotic stimulation after carbenoxolone injection into the lateral ventricle. Acta Anatomica Sinica, 2004; 35(2): $127-131$.

[2] Zhang T K. Technical reformation of ferromanganese BF. Jiangxi Metallurgy, 2002. (in Chineses)

[3] Yang Z, Robb D A. Partition coefficients of substrates and products and solvent selection for biocatalysis under nearly anhydrous conditions. Biotechnology \& Bioengineering, 1994; 43(5): 365-370.

[4] Sheng D, Gold M H. Haloperoxidase activity of manganese peroxidase from Phanerochaete chrysosporium. Archives of Biochemistry \& Biophysics, 1997; 345(1): 126.

[5] Han X, Wong Y S, Wong M H, Tam N F Y.. Feasibility of using microalgal biomass cultured in domestic wastewater for the removal of chromium pollutants. Water Environment Research, 2008, 80(7): 647-53.

[6] Li H Y, Xu Q L, Xue H S, Yan Y J.. Catalytic reforming of the aqueous phase derived from fast-pyrolysis of biomass. Renewable Energy, 2009; 34(12): 2872-2877.

[7] Patel D, Dayton P, Gut J, Wisner E, Ferrara K W. Optical and acoustical interrogation of submicron contrast agents. Ultrasonics Ferroelectrics \& Frequency Control IEEE Transactions, 2002; 49(12): 1641-1651.

[8] Devi L, Ptasinski K J, Janssen F J J G. A review of the primary measures for tar elimination in biomass gasification processes. Biomass \& Bioenergy, 2003; 24(2): 125-140.

[9] Wu B, Wang Z, Gong Q M, Song H H, Liang J. Fabrication and mechanical properties of in situ prepared mesocarbon microbead/carbon nanotube composites. Materials Science \& Engineering A, 2008; 487(1): 271-277.

[10] Wu X B, Wu J, Dan X Q, Zhang T P, Cao H. Application research of bamboo resources on rocky desertification control in China. World Forestry Research, 2015; 28(3): 37-41. (in Chinese)

[11] Luo A X. Study on microwave pyrolysis of bamboo residues and properties of its products. Nanchang: Nanchang University, 2007. (in Chinese)

[12] Wang X J, Wang Y, Wang X, Liu M, Xia S Q, Yin D Q, et al Microwave-assisted preparation of bamboo charcoal-based iron-containing adsorbents for $\mathrm{Cr}(\mathrm{VI})$ removal. Chemical Engineering Journal, 2011; 174(1): 326-332.

[13] Zhao R S, Yuan J P, Jiang T, Shi J B, Cheng C G. Application of bamboo charcoal as solid-phase extraction adsorbent for the determination of atrazine and simazine in environmental water samples by high-performance liquid chromatography-ultraviolet detector. Talanta, 2008; 76(4): 956-959.

[14] Zhu L, Huang Z H, Wen D, Kang F. Preparation and performance of biologically activated bamboo charcoal for removing quinoline. Journal of Physics and Chemistry of Solids, 2010; 71(4): 704-707.

[15] Zhang W B, Wang W L, Shao Q J, Fu Q H, Wong Y M, Qi W R. The present situation of the bamboo charcoal production process and the suggestion. Journal of Bamboo Research, 2003(1): 8-12. (in Chineses)

[16] Jung S, Kang B, Kim J. Production of bio-oil form rice straw and bamboo sawdust under various reaction conditions in a fast pyrolysis plant equipped with a fluidized bed and a char separation system. Journal of Analytical and Applied Pyrolysis, 2008; 82(2): 240-247.

[17] Qiao W M, Song Y, Huda M, Zhang X, Yoon S H, and Mochida I, et al. Development of carbon precursor from bamboo tar. Carbon, 2005; 43(14): 3021-3025.

[18] Prauchner M J, Pasa V, Otani S, Otani C. Biopitch-based general purpose carbon fibers: Processing and properties. Carbon, 2005; 43(3): 591-597.

[19] Home P A, Williams P T. Influence of temperature on the products from the flash pyrolysis of biomass. Fuel, 1996; 75(9): 1051-1059.

[20] Li S, Xu S, Liu S, Chen Y, Lu Q. Fast pyrolysis of biomass in free-fall reactor for hydrogen-rich gas. Fuel Processing Technology, 2004; 85(8-10): 1201-1211.

[21] GB/T 21923-2008, General testing rules for solid biofules, Beijing: China Standards Press, 2008.

[22] GB/T 28734-2012, Determination of carbon and hydrogen in solid biofuels, Beijing: China Standards Press, 2012.

[23] GB/T 30728-2014, Determination of nitrogen in solid biofuels Beijing: China Standards Press, 2014.

[24] Mehrabian R, Scharler R, Obernberger I. Effects of pyrolysis conditions on the heating rate in biomass particles and applicability of TGA kinetic parameters in particle thermal conversion modelling. Fuel, 2012; 93: 567-575.

[25] Maciejewski M. Computational aspects of kinetic analysis. Part B: the ICTAC Kinetics Project: the decomposition kinetics of calcium carbonate revisited, or some tips on survival in the kinetic minefield. Thermochim Acta, 2000; 355: 145-154.

[26] Vand V. A theory of the irreversible electrical resistance changes of 
metallic films evaporated in vacuum. Proc Phys Soc, 2002; 55(3): 222.

[27] Miura K, Maki T. A simple method for estimating $f(E)$ and $\mathrm{k} 0(\mathrm{E})$ in the distributed activation energy model. Energy Fuels, 1998; 12(5): 864-869.

[28] Miura K. A new and simple method to estimate $f(E)$ and $k 0(E)$ in the distributed activation energy model from three sets of experimental data. Energy Fuels, 1995; 9(2): 302-307.

[29] Ozawa T. A new method of analyzing thermogravimetric data. Bull Chem Soc Jpn, 1965; 38(11): 1881-1886.

[30] Yao F, Wu Q, Lei Y, Guo W, Xu Y. Thermal decomposition kinetics of natural fibers: activation energy with dynamic thermogravimetric analysis. Polym Degrad Stab, 2008; 93(1): 90-98.

[31] Grønli M G, Va'rhegyi G, Di Blasi C. Thermogravimetri analysis and devolatilization kinetics of wood. Ind Eng Chem Res, 2002; 41(17): 4201-4208.
[32] Taro S, Worasuwannarak N, Pipatmanomai S. Synergies in co-pyrolysis of Thai lignite and corncob. Fuel Processing Technology, 2008; 89(12): 1371-1378.

[33] Shen D K, Gu S, Jin B, Fang M X. Thermal degradation mechanisms of wood under inert and oxidative environments using DAEM methods. Bioresour Technol, 2011; 102(2): 2047-2052.

[34] Li C, Suzuki K. Kinetic analyses of biomass tar pyrolysis using the distributed activation energy model by TG/DTA technique. J Therm Anal Calorim, 2009; 98(1): 261-266.

[35] Di Blasi C. Modeling intra- and extra-particle processes of wood fast pyrolysis. AlChE J; 2002; 48(10): 2386-2397.

[36] Kumar A, Wang L, Dzenis Y A, Jones D D, Hanna M A. Thermogravimetric characterization of corn stover as gasification and pyrolysis feedstock. Biomass Bioenergy, 2008; 32(5): 460-467. 